\title{
Provoking New Images of Research and Practice in Reformed Educational Spaces
}

\author{
Chair: Robert Aiken (US) \\ Panel: David Passig (IL), Matti Sinko (FI)
}

Keywords: research, classroom practice, innovation, social issues, methodologies

Question: Why are (many) teachers not using computers in the classroom?

Answer: Because we are using old methods of teaching which do not adapt well to the new technologies

Solution: Be forward looking and examine what teachers WANT and try to find ways to find ways to address these needs.

Matti Sinko used a series of tables from some recent Finnish studies that showed that while students are using computers more outside class, that many report not using them in class. And this is in a country where $81 \%$ of schools report using computers in classrooms for children from the ages of $10-18$ ! So there is a major 'disconnect' and that missing piece must be the teacher. As additional evidence Matti noted that most of the ICT teachers are also teachers of mathematics. Yet when they teach mathematics almost none of them use a computer in their classroom! Schizophrenic - maybe - but more to the point the computer is not providing them with a tool that they feel allows them to do something different or better or.... than their current practices.

David Passig picked up on this theme by declaring that we have not begun to tap the potential of the computer for education. And we won't unless we develop completely new approaches for providing teachers something that they really want. He reported on a survey in which he participated in this past year that asked a wide range of teachers in North America what they would like the computer to do for them. The answers 
were not at all what were expected. Rather than mentioning education aspects they focused on emotional, psychological and social issues. They wanted to be able to better understand the student's emotional level as clues to their way(s) of thinking and learning. They wanted the computer to assist them in developing more open social environments - and environments that would allow them to respond to the psychological needs of their students. In other words, they were interested in qualitative aspects that have rarely been studied or even sufficiently well understood.

David's message was clear. We need to undertake research that examines these issues or the technology will not have an impact on education! We must start this process now and we must take risks. As one example he discussed some of his own research that in part is based on constructing Virtual Reality (VR) environments. He pointed to the need for providing teacher scaffolding as a way to help them use computers to construct better environments for their students. As one example he briefly discussed a VR environment his research group has constructed that allows the user (teacher) to enter the world of a young child (5-6 years old) and 'feel' what the world looks like from the perspective of the child. Another example he discussed was how students are learning (and we are not studying) using hand held communication devices. There is an entire culture that has been created and is natural for young people to use, BUT there is little to no research on how we can/should incorporate such technology and ethos into the learning process.

So the message is clear: Change the way and types of research we are doing to explore what teachers really need and want or risk losing the opportunity which this technology provides! 